\title{
Residual lymph node disease and mortality following neoadjuvant chemoradiation and curative esophagectomy for distal esophageal adenocarcinoma
}

Apostolos Kandilis, MD, ${ }^{\mathrm{a}}$ Carlos Bravo Iniguez, MD, ${ }^{\mathrm{a}}$ Hassan Khalil, MD, ${ }^{\mathrm{a}}$ Emanuele Mazzola, MS, PhD, ${ }^{\mathrm{b}}$ Michael T. Jaklitsch, MD, ${ }^{\text {a }}$ Scott J. Swanson, MD, ${ }^{a}$ Raphael Bueno, MD, ${ }^{a}$ and Jon O. Wee, MD $^{\mathrm{a}}$

\section{ABSTRACT}

Objectives: Neoadjuvant chemoradiation has been shown to improve survival in locally advanced esophageal and gastroesophageal junction cancer. The purpose of our study was to examine the effects of posttreatment persistent lymph node (LN) disease on overall survival (OS) and recurrence in patients with esophageal adenocarcinoma after neoadjuvant chemoradiation as well as the effect of LN harvest and the potential benefit of adjuvant chemotherapy.

Methods: The records of patients who underwent esophagectomy in our hospital from January 2005 until December 2016 were analyzed. Our study group consisted of 509 patients.

Results: Patient groups were created based on pathologic staging after esophagectomy (yPT N) as $22.0 \%$ of patients were ypTo No, $46.2 \%$ had incomplete response only at the primary tumor level (yPT + No), and $31.8 \%$ had at least 1 metastatic lymph node (ypTx N+). Median OS was 58.3 months. The ypTx $\mathrm{N}+$ group was divided into ypTx $\mathrm{N}_{1}$ and ypTx $\mathrm{N}_{2}$ or $\mathrm{N}_{3}$ subgroups based on the number of metastatic lymph nodes. The OS between the 2 groups was not significantly different (median OS, 37.6 vs 29.8 months; $P=.097$ ). The disease-free survival did show a statistically significant difference (median disease-free survival, 27.6 vs 13.7 months; $P=.007$ ). The LN harvest was not found to be significantly associated with OS. However, administration of adjuvant chemotherapy was a significant prognosticator for increased OS (hazard ratio, 0.590; $P=.043$ ).

Conclusions: Our results demonstrate that residual LN disease after neoadjuvant chemoradiation is associated with increased mortality. Adjuvant chemotherapy, but not number of LNs resected, was correlated with increased OS in this subset of patients. (JTCVS Open 2021;5:135-47)

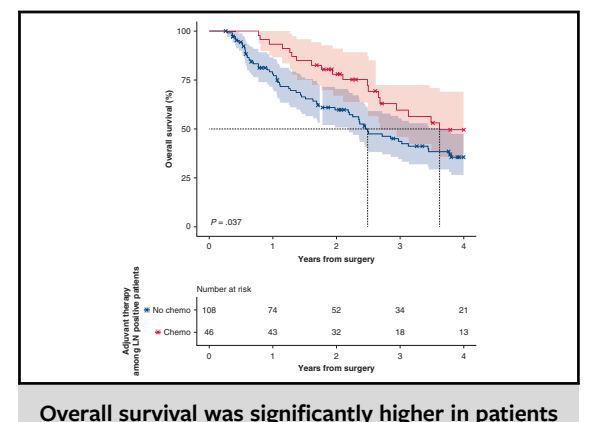

Overall survival was significantly higher in patients who received adjuvant treatment.

\section{CENTRAL MESSAGE}

Adjuvant chemotherapy, but not number of lymph nodes resected, is associated with increased overall survival in patients with residual lymph node disease.

\section{PERSPECTIVE}

Node-positive patients with distal esophageal adenocarcinoma after neoadjuvant chemoradiation had decreased survival and potentially disseminated disease. The extent of lymphadenectomy did not have an effect on survival. Adjuvant treatment was associated with increased overall survival and should be considered in patients with residual lymph node disease.

See Commentaries on pages 148 and 150.
From the ${ }^{a}$ Department of Thoracic Surgery, Brigham and Women's Hospital, Harvard Medical School, Boston, Mass; and 'bepartment of Data Science, Dana-Farber Cancer Institute, Boston, Mass.

Accepted for the 100th Annual Meeting of The American Association for Thoracic Surgery.

Received for publication Dec 7, 2020; accepted for publication Dec 8, 2020; available ahead of print Jan 8, 2021.

Address for reprints: Jon O. Wee, MD, Division of Thoracic Surgery, Brigham and Women's Hospital, Harvard Medical School, 75 Francis St, Boston, MA 02115 (E-mail: jwee@bwh.harvard.edu).

2666-2736

Copyright (C) 2020 The Authors. Published by Elsevier Inc. on behalf of The American Association for Thoracic Surgery. This is an open access article under the CC BY-NCND license (http://creativecommons.org/licenses/by-nc-nd/4.0/).

https://doi.org/10.1016/j.xjon.2020.12.001
The role of neoadjuvant chemoradiation (nCRT) in improving survival for patients with locally advanced esophageal and gastroesophageal junction cancer has been well documented. ${ }^{1,2}$ The complete pathologic response (CR) rates following neoadjuvant treatment has been reported as high as $53 \%$, with lower rates in patients with adenocarcinoma (AC) versus squamous cell cancer (SCC). ${ }^{3}$ A complete pathologic response is associated with improved long-term survival. ${ }^{4}$ However, a significant percentage of patients have either partial response of the primary tumor, residual lymph node (LN) metastases, or both. 


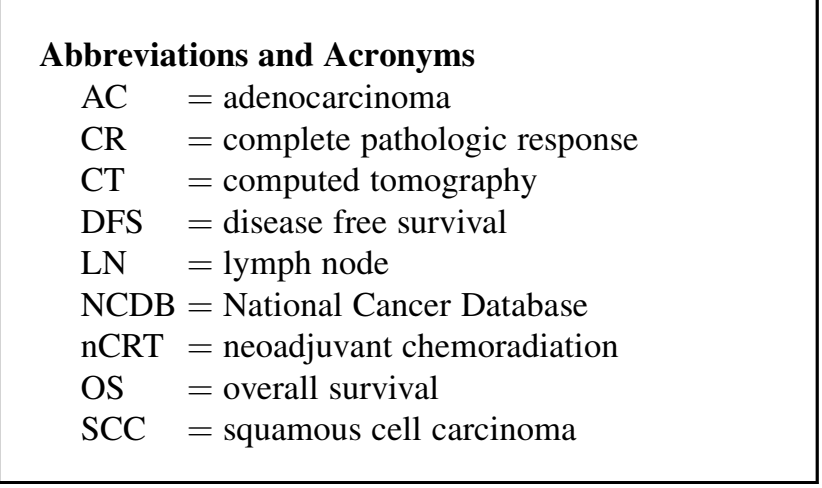

LN metastasis is associated with a poor prognosis in esophageal cancer. Rice and colleagues showed that in patients after esophagectomy without nCRT, the increasing number of positive nodes and increasing $\mathrm{pN}$ classification were associated with deeper invading, longer, and poorly differentiated cancers. ${ }^{5}$ The National Comprehensive Cancer Network guidelines recommend the resection of at least $15 \mathrm{LNs}$ in esophagectomies without nCRT to ensure appropriate staging. ${ }^{6}$ In cases of nCRT, there is no clear recommendation regarding the extent of LN dissection. The extent of lymphadenectomy required at the time of surgery and its effect on overall prognosis is not uniformly embraced. $^{7-9}$ This becomes more controversial if one considers AC and SCC as 2 different biologic entities based on their different response to nCRT. Studies regarding the extent of lymphadenectomy recommended for AC and SCC are also conflicting. ${ }^{10,11}$

The role of adjuvant treatment in postresection nodepositive patients also remains unclear. The National Comprehensive Cancer Network guidelines recommend surveillance until disease progression for patients with AC or SCC after complete resection following nCRT regardless of their nodal status. ${ }^{6}$ However, recent studies have demonstrated survival benefit of adjuvant treatment for patients with persistent positive LNs after induction therapy and surgery. ${ }^{12,13}$

The purpose of our study was to examine the effects of posttreatment persistent $\mathrm{LN}$ disease on overall survival (OS) and recurrence in patients with distal esophageal AC after nCRT as well as the potential benefit of adjuvant chemotherapy. We also hypothesized that for these patients, it is the adjuvant treatment that can have a potentially beneficial influence on OS and not the extent of lymphadenectomy.

\section{METHODS}

The work described was conducted with institutional review board approval (No. 2015P000752; April 2015). The institutional review board waived the need for informed written consent for publication. The records of patients who underwent esophagectomy (883 patients) at the Brigham and Women's Hospital from January 2005 until December 2016 were analyzed. We applied the following inclusion and exclusion criteria: only patients with distal AC (752 patients), post-nCRT (587 patients), R0 resections (553 patients), without metastatic disease at the time of surgery (547 patients), esophagectomies within 4 to 8 weeks after nCRT, and $>90$-day survival (517 patients). ${ }^{14}$ Files were retrieved and continued follow-up was confirmed for 509 patients who were included in our study.

The preoperative staging included computed tomography (CT) of the chest/abdomen, and a positron-emission tomography scan and/or endoscopic ultrasound in most cases. The administration of nCRT was according to the Chemoradiotherapy for Esophageal Cancer Followed by Surgery Study protocol or with a combination of fluorouracil/cisplatin and radiation dose was between 41.4 and 50.4 Gy. Following nCRT, repeat positron-emission tomography was performed to exclude metastatic disease. Two types of esophagectomies were performed: the Ivor Lewis and 3-hole esophagectomies (modified McKeown ${ }^{15}$ ). The surgical approach was minimally invasive, open, or hybrid. The abdominal part was performed either open or laparoscopically, and the thoracic part open, thoracoscopically, or robotic-assisted.

Patients were assigned to 3 different cohorts based on pathological examination of the esophagectomy specimens. The American Joint Committee on Cancer eighth edition was used for the TNM classification. Group I had no viable tumor cells in the esophagus or LNs (ypT0 N0) and were defined as CR. Group II had residual primary tumor without evidence of LN metastases (ypT $+\mathrm{N} 0$ ). Group III had residual LN disease regardless of the primary tumor response (ypTx $\mathrm{N}+$ ). The latter group was subdivided based on the number of metastatic lymph nodes into 2 groups: ypTx N1 (with 1-2 positive LNs) and ypTx N2 or N3 (with $>3$ positive LNs).

Variables analyzed included demographic characteristics, tumor location defined as upper (cervical esophagus to azygos), middle (azygos to lower border of inferior pulmonary vein), and lower (including gastroesophageal junction tumors), type of surgery and approach, pretreatment clinical $\mathrm{T}$ and $\mathrm{N}$ stages, number of LNs retrieved, ratio between positive LNs to total number of LNs retrieved (LN ratio) with break point set at $0.2^{1,14,16}$ perineural invasion, presence of lymphovascular and venous invasion, presence of signet ring cells, locoregional and distant metastases, and administration of adjuvant treatment. Patients, who only received palliative chemotherapy after the identification of recurrence, were included in the group of patients without adjuvant chemotherapy.

Following surgery and discharge from the hospital, regular follow-up visits were scheduled at 2 weeks and 1 month postoperatively. The first postoperative CT scan was performed at 4 months and then follow-up continued every 4 to 6 months with CT scans for 2 years. After 2 years, surveillance was every 6 to 12 months with a clinic visit and CT scan.

\section{STATISTICAL ANALYSIS}

Analysis for OS and disease-free survival (DFS) was performed with Kaplan-Meier curves using the log-rank test for comparison. Differences in patient characteristics were estimated by means of the Mann-Whitney $U$ test for continuous variables not normally distributed, and $\chi^{2}$ tests for categorical variables. OS was calculated from the date of surgery to the date of death or last follow-up and DFS from the date of surgery to the date of disease recurrence. We used medians and $95 \%$ confidence interval (CI) for both OS and DFS. In instances where the estimated survival probability never reached $50 \%$ (ie, there was no result for the median survival), survival rates with standard errors were used. We used univariable and multivariable Cox models for the evaluation of the effect of the risk factors on both OS and DFS. Variables that were found to be statistically significant in the univariate models were 
TABLE 1. Clinical characteristics of patients undergoing esophagectomy for esophageal adenocarcinoma after neoadjuvant chemoradiation

\begin{tabular}{|c|c|c|c|c|}
\hline Variable & ypT0 No $(n=112[22.0 \%])$ & ypT + No $(n=235[46.2 \%])$ & $\operatorname{ypTx} N+(n=162[31.8 \%])$ & $P$ value \\
\hline Age (y) & & & & .687 \\
\hline$<65$ & $63(56.3)$ & $129(54.9)$ & $96(59.3)$ & \\
\hline$\geq 65$ & $49(43.8)$ & $106(45.1)$ & $66(40.7)$ & \\
\hline Gender & & & & .351 \\
\hline Male & $93(83.0)$ & $208(88.5)$ & $142(87.7)$ & \\
\hline Female & $19(17.0)$ & $27(11.5)$ & $20(12.3)$ & \\
\hline Type of surgery & & & & .042 \\
\hline 3-hole (modified McKeown) & $59(52.7)$ & $109(46.4)$ & $61(37.7)$ & \\
\hline Ivor Lewis & $53(47.3)$ & $126(53.6)$ & $101(62.3)$ & \\
\hline Surgical approach & & & & .571 \\
\hline Open & $22(19.6)$ & $54(23.0)$ & $38(23.5)$ & \\
\hline MIE & $80(71.4)$ & $149(63.4)$ & $102(63.0)$ & \\
\hline Hybrid & $10(8.9)$ & $32(13.6)$ & $22(13.5)$ & \\
\hline $\mathrm{cT}$ & & & & .114 \\
\hline $\mathrm{T} 1$ & $7(6.3)$ & $5(2.1)$ & $1(0.6)$ & \\
\hline $\mathrm{T} 2$ & $24(21.4)$ & $50(21.3)$ & $26(16.0)$ & \\
\hline $\mathrm{T} 3$ & $64(57.1)$ & $138(58.7)$ & $98(60.5)$ & \\
\hline $\mathrm{T} 4$ & $1(0.9)$ & $2(0.9)$ & $3(1.9)$ & \\
\hline $\mathrm{n} / \mathrm{r}$ & $16(14.3)$ & $40(17.0)$ & $34(21.0)$ & \\
\hline $\mathrm{cN}$ & & & & .010 \\
\hline No & $28(25.0)$ & $78(33.2)$ & $38(23.5)$ & \\
\hline N1 & $59(52.7)$ & $113(48.1)$ & $91(56.2)$ & \\
\hline $\mathrm{N} 2$ & $13(11.6)$ & $15(6.4)$ & $17(10.5)$ & \\
\hline N3 & $3(2.7)$ & 0 & 0 & \\
\hline $\mathrm{n} / \mathrm{r}$ & $9(8.0)$ & $29(12.3)$ & $16(9.9)$ & \\
\hline Clinical stage & & & & .002 \\
\hline I & $7(6.3)$ & $4(1.7)$ & $1(0.6)$ & \\
\hline II & $39(34.8)$ & $105(44.7)$ & $47(29.0)$ & \\
\hline III & $46(41.1)$ & $83(35.3)$ & $77(47.5)$ & \\
\hline IVA & $4(3.6)$ & $2(0.9)$ & $3(1.9)$ & \\
\hline $\mathrm{n} / \mathrm{r}$ & $16(14.3)$ & $41(17.4)$ & $34(21.0)$ & \\
\hline LNs removed & & & & .456 \\
\hline$<15$ & $33(29.5)$ & $73(31.0)$ & $41(25.3)$ & \\
\hline$\geq 15$ & $79(70.5)$ & $162(73.0)$ & $121(74.7)$ & \\
\hline Perineural invasion & & & & $<.0001$ \\
\hline Present & 0 & $33(14.0)$ & $50(30.9)$ & \\
\hline Absent & $107(100.0)$ & $202(86.0)$ & $112(69.1)$ & \\
\hline Lymphovascular invasion & & & & $<.0001$ \\
\hline Present & $1(0.9)$ & $28(11.9)$ & $58(36.0)$ & \\
\hline Absent & $106(99.1)$ & $207(88.1)$ & $103(64.0)$ & \\
\hline Venous invasion & & & & .010 \\
\hline Present & 0 & $9(3.9)$ & $12(7.6)$ & \\
\hline Absent & 107 (100.0) & $224(96.1)$ & $146(92.4)$ & \\
\hline Signet ring cells & & & & .113 \\
\hline Present & $8(7.1)$ & $32(13.6)$ & $25(15.4)$ & \\
\hline Absent & $104(92.9)$ & $203(86.4)$ & $137(84.6)$ & \\
\hline Locoregional recurrence & & & & $<.0001$ \\
\hline Present & $8(7.1)$ & $36(15.3)$ & $40(24.7)$ & \\
\hline Absent & $104(92.9)$ & $199(84.7)$ & $122(75.3)$ & \\
\hline Distant recurrence & & & & .001 \\
\hline Present & $25(22.3)$ & $83(35.3)$ & $72(44.4)$ & \\
\hline Absent & $87(77.7)$ & $152(64.7)$ & $90(55.6)$ & \\
\hline
\end{tabular}

Values are presented as n (\%). ypTO NO, Complete pathologic response; $y p T+N O$, residual primary tumor, but no metastatic lymph nodes; $y p T x N+$, residual lymph nodes regardless of primary tumor; $M I E$, minimally invasive esophagectomy; $c T$, clinical T status; $n / r$, no record; $c N$, clinical $\mathrm{N}$ status; $L N$, lymph nodes. 

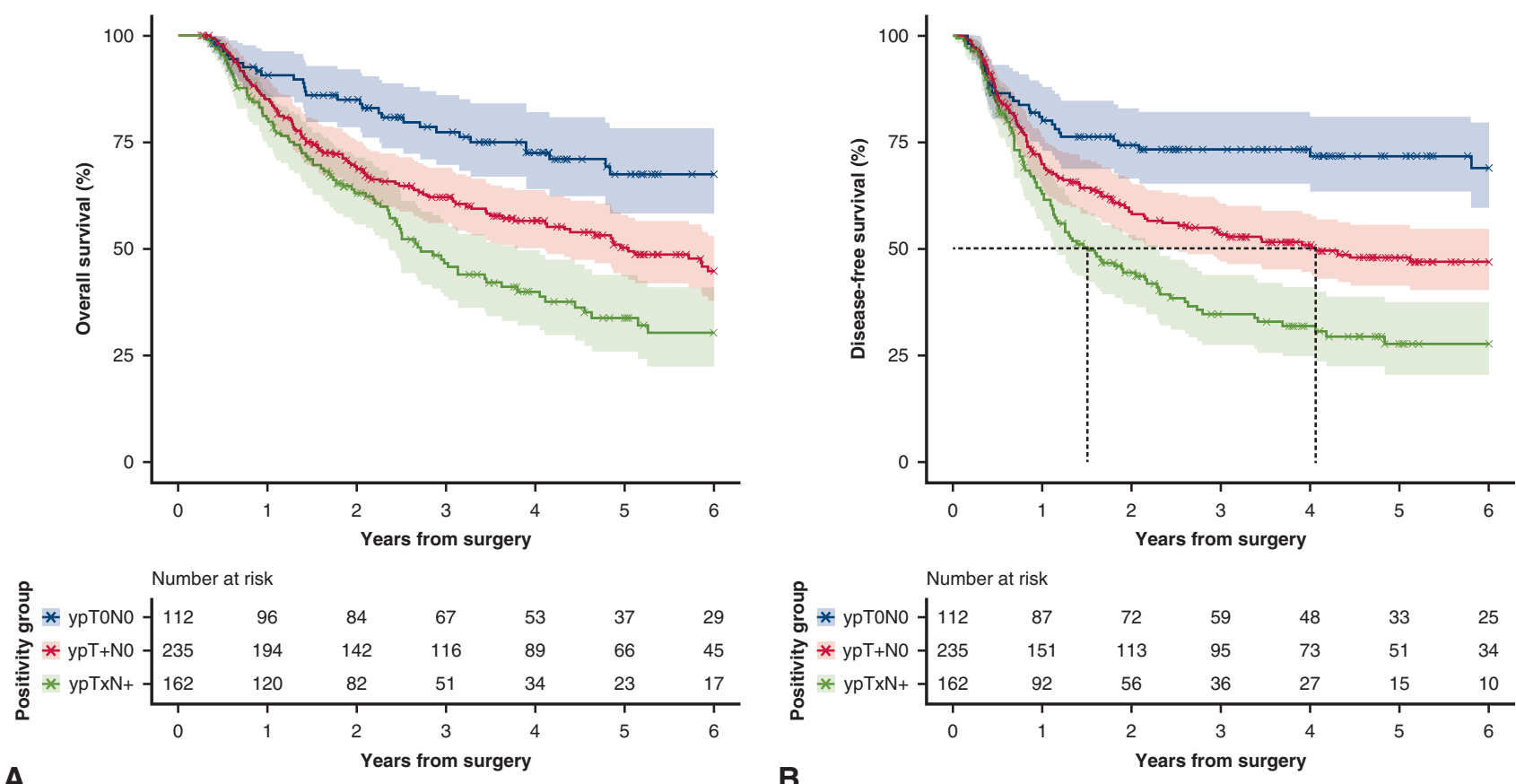

FIGURE 1. Patients with esophageal adenocarcinoma undergoing esophagectomy after neoadjuvant chemoradiation according to pathologic response of primary tumor and lymph nodes. A, Overall survival. B, Disease-free survival. ypTO NO, Complete pathologic response; ypT $+N O$, residual primary tumor, but no metastatic lymph nodes; $y p T x N+$, residual lymph nodes regardless of primary tumor.

included in the corresponding multivariable. Results were expressed as hazards ratios (HRs) with 95\% CIs. All analyses were performed using $\mathrm{R}$ version 3.6.0 (R Foundation for Statistical Computing, Vienna, Austria).

\section{RESULTS}

Median follow-up after surgery was 60.0 months $(95 \%$ CI, 55.1-63.7 months), and $112(22.0 \%)$ patients were noted to have pathological CR (Group I), whereas 235 $(46.2 \%)$ patients were ypT + N0 (Group II), and 162 $(31.8 \%)$ patients had residual cancer in their LN (Group III). The Ivor Lewis approach was performed in 280 $(55.0 \%)$ patients and 3-hole esophagectomy in 229 $(45.0 \%)$ patients. A minimally invasive approach was utilized in $331(65.0 \%)$ of cases. The 3 groups showed significant differences in the type of surgery, clinical $\mathrm{N}$ status, and clinical stage, perineural, venous and lymphovascular invasion, as well as the locoregional and distant recurrence status (Table 1).

\section{Survival}

Median OS was 58.3 months (95\% CI, 49.3-86.8 months). Three-year OS of ypT0 N0, ypT + N0 and ypTx N+ patients was $77.47 \% \pm 4.2 \%, 62.2 \% \pm 3.3 \%$, and $46.7 \% \pm 4.4 \%$, respectively. Five-year OS of ypT0 N0, ypT $+\mathrm{N} 0$, and ypTx $\mathrm{N}+$ were $67.5 \% \pm 5.1 \%, 50.2 \% \pm 3.7 \%$, and $33.7 \% \pm 4.5 \%$, respectively (all pairwise log-rank test $P$ values $<.01$ ) (Figure 1, $A$ ). Three-year DFS of ypT0 N0,
ypT + N0, and ypTx N+ patients was $73.3 \% \pm 4.3 \%$, $53.4 \% \pm 3.4 \%$, and $34.7 \% \pm 4.1 \%$, respectively. Five-year DFS of ypT0 N0, ypT + N0, and ypTx N+ was $71.7 \% \pm 4.4 \%, 47.9 \% \pm 3.6 \%$, and $27.7 \% \pm 4.2 \%$, respectively (all pairwise log-rank test $P$ values $<.01$ ) (Figure 1, B).

The ypTx $\mathrm{N}+$ group was divided into 2 subgroups ypTx $\mathrm{N} 1$ and ypTx N2 or N3 based on the number of metastatic lymph nodes. The median OS for group ypTx N1 was 37.6 months, whereas for group ypTx $\mathrm{N} 2$ or $\mathrm{N} 3$ was 29.8 months. The difference in OS was not statistically significant $(P=.097)$ (Figure $2, A)$. On the other hand, the DFS was significantly higher in the ypTx N1 versus the ypTx N2 or N3 group $(P=.007)$ (Figure $2, B)$. The median DFS was 27.6 and 13.7 months for the 2 groups, respectively.

\section{LN Harvest}

Fifteen or more LNs were resected in $372(71.1 \%)$ patients (range, $2-75 \mathrm{LNs}$ ). Only 5 patients $(0.9 \%)$ in the total cohort and only 1 of $162(0.6 \%)$ patients with residual $\mathrm{LN}$ disease had $<5 \mathrm{LNs}$ retrieved. We divided our 12-year study period into 26 -year periods (first and second) and compared the median numbers of LNs retrieved per period. The median number of LNs in the first period was 16 (range, 2-40 LNs) and was statistically lower compared with that in the second period, where the median number was $19 \mathrm{LNs}$ (range, $4-75 \mathrm{LNs})(P=.001)$. 

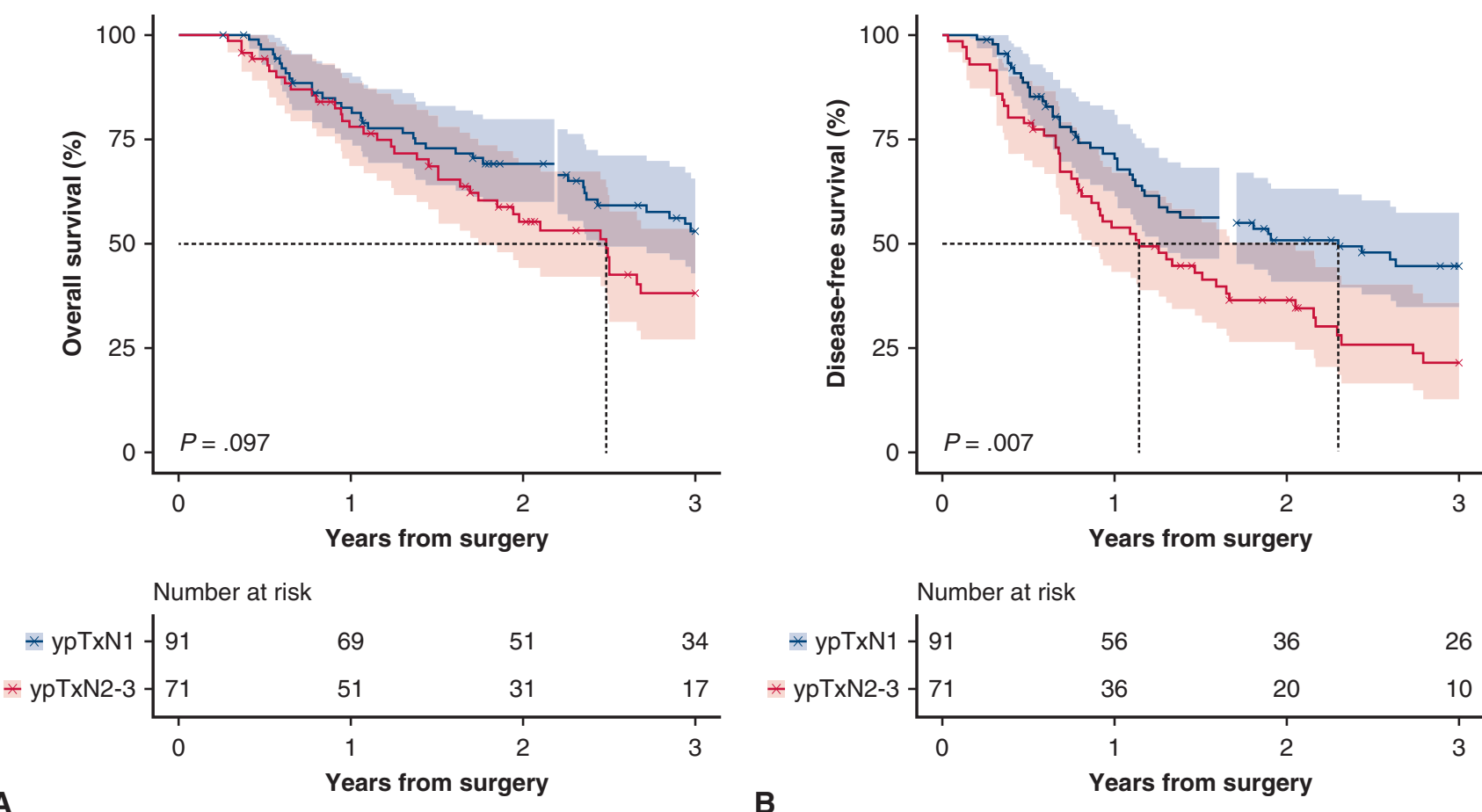

FIGURE 2. Survival curves in patients with esophageal adenocarcinoma with residual lymph node disease after neoadjuvant chemoradiation and esophagectomy, regardless of the pathological response of primary tumor. (The $x$-axis for survival in years was cut at the time point when $<10$ patients were at risk.). A, Overall survival. The median overall survival of ypTx N1 and ypTx N2 or N3 patients was 37.6 months (95\% confidence interval, 29.2-61.8 months) and 29.8 months (95\% confidence interval, 20.9-41.2 months), respectively. B, Disease-free survival. The median disease free survival of ypTx N1 and ypTx N2 or N3 patients was 27.6 months (95\% confidence interval, 15.1-39.3 months) and 13.7 months (95\% confidence interval, 10.4-24.6 months), respectively. ypTx $N+$, Residual lymph nodes regardless of primary tumor.

We also compared OS in patients with 15 or more LNs resected and those with fewer LNs removed. The median OS was 68.6 months for patients with 15 or more LNs retrieved, higher compared with 46.8 months for those with fewer LNs. However, the difference in OS did not reach statistical significance $(P=.085)$ (Figure 3,A). Similar results were demonstrated in the subgroup analysis of patients with residual LN disease, with no significant difference in OS demonstrated between patients with 15 or more LNs resected (120 out of 162 patients [74.1\%]) and those with fewer (42 patients [25.9\%]) $(P=.470)$ (Figure 3, B). We also examined whether a more extended lymphadenectomy would be beneficial for OS in patients with residual LNs. The median OS in patients with 21 or more LNs resected (62 out of 162 patients [38.3\%]) was 29.9 months, similar to 34.2 months for patients with fewer than 21 LNs removed (100 patients [61.7\%]). No significant difference in OS was demonstrated in patients with 21 or more LNs resected versus fewer LNs $(P=.670)$.

\section{Adjuvant Treatment}

In patients with residual LNs who either received or not adjuvant chemotherapy, there were no differences in age, gender, type of surgery, surgical approach, clinical stage, perineural, lymphovascular or venous invasion, and the presence of locoregional recurrence (Table 2). Both groups were more likely to have distant compared with locoregional recurrence. In particular, in the group without adjuvant treatment the rates for locoregional and distant recurrence were 24 out of $108(22.2 \%)$ and 52 out of 108 $(48.1 \%)$, respectively, and in the group with adjuvant treatment the rates were 13 out of $46(28.3 \%)$ and 17 out of $46(37.0 \%)$, respectively. Nine patients who did not receive adjuvant treatment had simultaneous locoregional and distant metastases at the diagnosis of recurrence and 2 patients in the group that received adjuvant treatment. The group with administration of adjuvant treatment was found to have significantly higher ypTNM stage, compared with the group without adjuvant treatment. In particular, 32 out of $46(69.6 \%)$ patients had stage IIIB and $9(19.6 \%)$ had stage IVA, compared with 61 out $108(56.5 \%)$ and 9 out of $108(8.3 \%)$, respectively. Furthermore, patients who received adjuvant treatment had higher percentage of both grade 3 differentiation (33 out of 46 patients [71.7\%]) and $L N$ ratio $>0.2$ (17 out of 46 patients [37.0\%]) compared with patients without adjuvant treatment (58 out of 108 patients [53.7\%] and 22 out of 108 patients [20.4\%], respectively). 

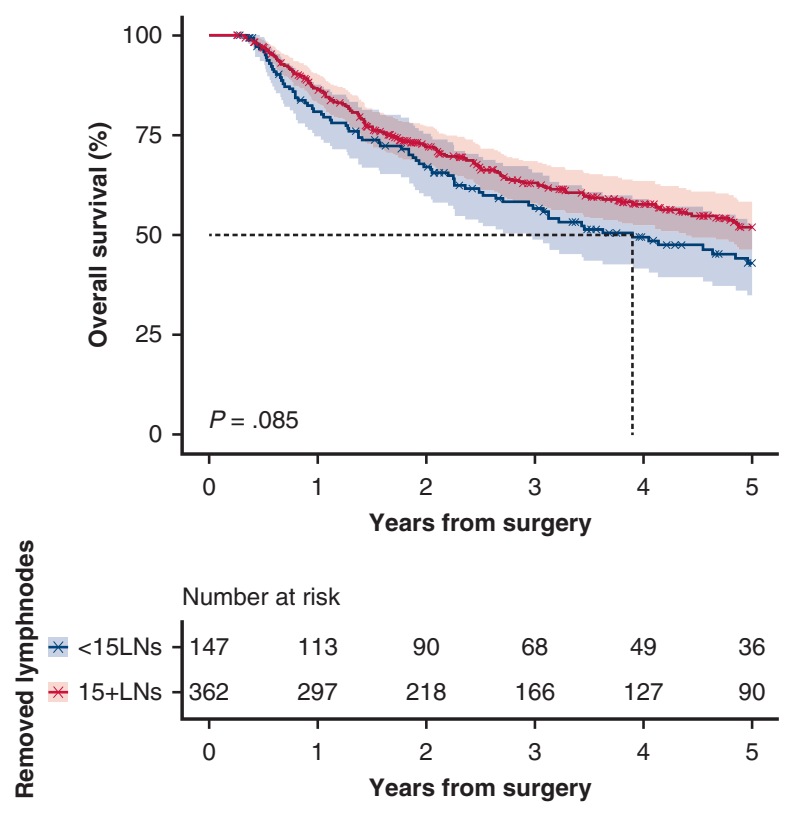

A
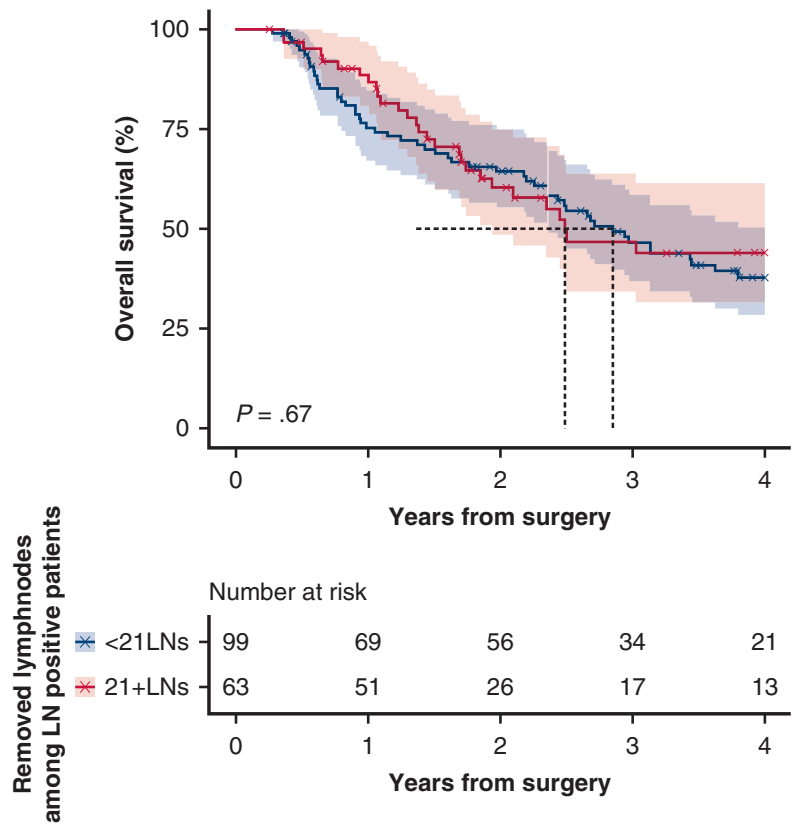
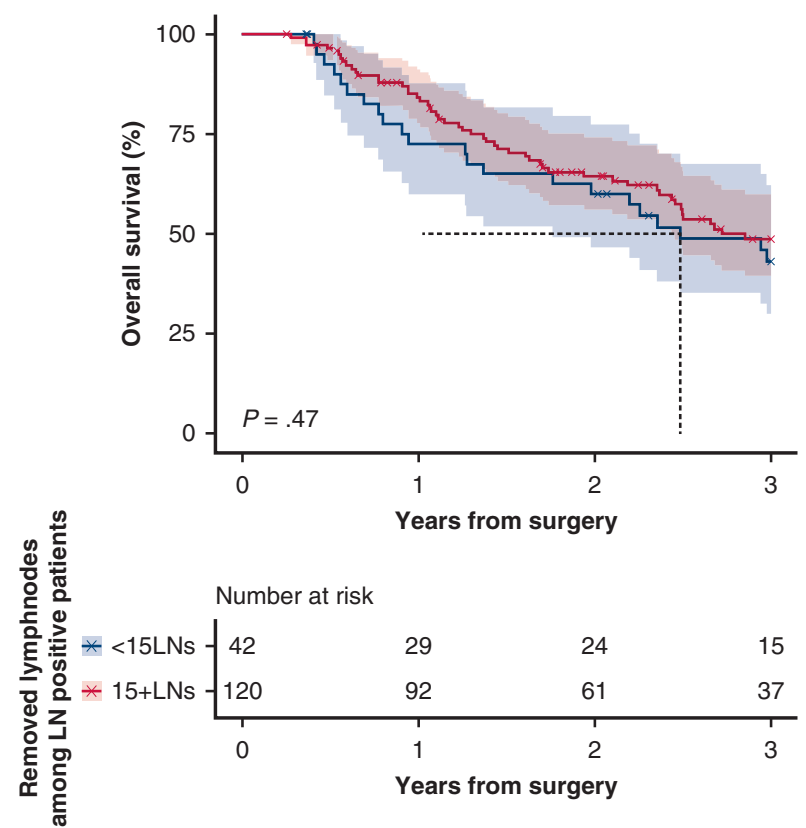

B

C

FIGURE 3. Survival curves based on the number of lymph nodes (LNs) resected. (The $x$-axis for survival in years was cut at the time point when $<10$ patients were at risk.). A, Overall survival in patients with 15 or more lymph nodes resected after neoadjuvant chemoradiation and esophagectomy for distal esophageal adenocarcinoma was not significantly different compared with patients with fewer lymph nodes removed $(P=.085)$. B, In patients with residual lymph node disease, harvest of 15 or more lymph nodes was not associated with significantly different survival compared with fewer lymph nodes $(P=.470)$. C, In patients with residual lymph node disease, more extensive lymphadenectomy of 21 or more lymph nodes was not associated with significantly different overall survival compared with fewer lymph nodes $(P=.670)$.

In regard to survival, the median OS in patients who received adjuvant treatment was 43.4 months, higher compared with 29.8 months in patients without adjuvant treatment. OS was found to be significantly higher in the patients receiving adjuvant treatment $(P=.037)$. The median DFS was 25.9 months in the group with adjuvant treatment compared to 15.1 months for the group without adjuvant treatment. The difference in DFS did not reach 
TABLE 2. Clinical characteristics of 162 patients with residual lymph node disease, based on administration or not of adjuvant chemotherapy

\begin{tabular}{|c|c|c|c|c|}
\hline Variable & $\begin{array}{l}\text { No adjuvant chemotherapy } \\
(n=108[66.7 \%])\end{array}$ & $\begin{array}{l}\text { Adjuvant chemotherapy } \\
\qquad(\mathrm{n}=\mathbf{4 6}[28.4 \%])\end{array}$ & $P$ value & $\begin{array}{c}\text { Missing data } \\
(\mathrm{n}=8[4.9 \%])\end{array}$ \\
\hline Age (y) & & & .406 & \\
\hline$<65$ & $61(56.5)$ & $30(65.2)$ & & $6(75)$ \\
\hline$\geq 65$ & 47 (43.5) & $16(34.8)$ & & $2(25)$ \\
\hline Gender & & & .946 & \\
\hline Male & $96(88.9)$ & $40(87.0)$ & & $7(87.5)$ \\
\hline Female & $12(11.1)$ & $6(13.0)$ & & $1(12.5)$ \\
\hline Type of surgery & & & .305 & \\
\hline 3-hole & 44 (40.7) & $14(30.4)$ & & $5(62.5)$ \\
\hline Ivor Lewis & $64(59.3)$ & $32(69.6)$ & & $3(37.5)$ \\
\hline Surgical approach & & & .578 & \\
\hline Open & $25(23.1)$ & $12(65.2)$ & & $4(50.0)$ \\
\hline MIE & $67(62.0)$ & $30(26.1)$ & & $3(37.5)$ \\
\hline Hybrid & $16(14.8)$ & $4(8.7)$ & & $1(12.5)$ \\
\hline $\mathrm{cT}$ & & & .495 & \\
\hline $\mathrm{T} 1$ & 0 & $1(2.2)$ & & 0 \\
\hline $\mathrm{T} 2$ & $18(16.7)$ & $7(15.2)$ & & $1(12.5)$ \\
\hline $\mathrm{T} 3$ & $66(61.1)$ & $28(60.9)$ & & $5(67.5)$ \\
\hline $\mathrm{T} 4$ & $2(1.9)$ & $1(2.2)$ & & 0 \\
\hline $\mathrm{n} / \mathrm{r}$ & $22(20.4)$ & 9 (19.6) & & $2(25.0)$ \\
\hline $\mathrm{cN}$ & & & .497 & \\
\hline No & $23(21.3)$ & $14(30.4)$ & & 0 \\
\hline N1 & $64(59.3)$ & $24(52.2)$ & & $5(67.5)$ \\
\hline $\mathrm{N} 2$ & $10(9.3)$ & $4(8.7)$ & & $2(25.0)$ \\
\hline N3 & 0 & 0 & & 0 \\
\hline $\mathrm{n} / \mathrm{r}$ & $11(10.2)$ & $4(8.7)$ & & $1(12.5)$ \\
\hline Clinical stage & & & .435 & \\
\hline I & 0 & $1(2.2)$ & & 0 \\
\hline II & $31(28.7)$ & $15(32.6)$ & & 0 \\
\hline III & $53(49.1)$ & $20(43.5)$ & & $6(75.0)$ \\
\hline IVA & $2(1.9)$ & $1(2.2)$ & & 0 \\
\hline $\mathrm{n} / \mathrm{r}$ & $22(20.4)$ & $9(19.6)$ & & $2(25.0)$ \\
\hline урТ & & & .011 & \\
\hline T0 & $1(0.9)$ & $2(4.3)$ & & 0 \\
\hline $\mathrm{T} 1$ & $16(14.8)$ & $2(4.3)$ & & 0 \\
\hline $\mathrm{T} 2$ & $28(25.9)$ & $4(8.7)$ & & $1(12.5)$ \\
\hline $\mathrm{T} 3$ & $62(57.4)$ & $38(82.6)$ & & $7(87.5)$ \\
\hline $\mathrm{T} 4$ & $1(0.9)$ & 0 & & 0 \\
\hline ypN & & & .091 & \\
\hline N1 & $70(64.8)$ & $23(50.0)$ & & $1(12.5)$ \\
\hline $\mathrm{N} 2$ & $29(26.9)$ & $14(30.4)$ & & $5(62.5)$ \\
\hline N3 & $9(8.3)$ & $9(19.6)$ & & $2(25.0)$ \\
\hline ypTNM stage & & & .004 & \\
\hline IIIA & $38(35.2)$ & $5(10.9)$ & & $1(12.5)$ \\
\hline IIIB & $61(56.5)$ & $32(69.6)$ & & $5(62.5)$ \\
\hline IVA & $9(8.3)$ & 9 (19.6) & & $2(25.0)$ \\
\hline LNs removed & & & .043 & \\
\hline$<15$ & $23(21.3)$ & $17(37.0)$ & & $2(25.0)$ \\
\hline$\geq 15$ & 85 (78.7) & $29(63.0)$ & & $6(75.0)$ \\
\hline $\mathrm{LN}$ ratio & & & .050 & \\
\hline$\leq 0.2$ & $86(79.6)$ & $29(63.0)$ & & $4(50.0)$ \\
\hline$>0.2$ & $22(20.4)$ & $17(37.0)$ & & $4(50.0)$ \\
\hline
\end{tabular}


TABLE 2. Continued

\begin{tabular}{|c|c|c|c|c|}
\hline Variable & $\begin{array}{l}\text { No adjuvant chemotherapy } \\
\quad(n=108[66.7 \%])\end{array}$ & $\begin{array}{l}\text { Adjuvant chemotherapy } \\
\qquad(\mathrm{n}=46[28.4 \%])\end{array}$ & $P$ value & $\begin{array}{l}\text { Missing data } \\
(n=8[4.9 \%])\end{array}$ \\
\hline Grade & & & .015 & \\
\hline 1 & $4(3.7)$ & $3(6.5)$ & & 0 \\
\hline 2 & $43(39.8)$ & $7(15.2)$ & & $3(37.5)$ \\
\hline 3 & $58(53.7)$ & 33 (71.7) & & $5(62.5)$ \\
\hline $\mathrm{n} / \mathrm{r}$ & $3(2.8)$ & $3(6.5)$ & & 0 \\
\hline Perineural invasion & & & .148 & \\
\hline Present & $28(25.9)$ & $18(39.1)$ & & $5(62.5)$ \\
\hline Absent & $80(74.1)$ & $28(60.9)$ & & $3(37.5)$ \\
\hline Lymphovascular invasion & & & .884 & \\
\hline Present & $33(30.6)$ & $15(32.6)$ & & $2(25.0)$ \\
\hline Absent & $75(69.4)$ & $31(67.4)$ & & $6(75.0)$ \\
\hline Signet ring cells & & & .976 & \\
\hline Present & $19(17.6)$ & $8(17.4)$ & & 0 \\
\hline Absent & $89(82.4)$ & $38(82.6)$ & & $8(100.0)$ \\
\hline Venous invasion & & & .673 & \\
\hline Present & $6(3.3)$ & $4(9.1)$ & & $2(25.0)$ \\
\hline Absent & $102(96.7)$ & $40(90.9)$ & & $6(75.0)$ \\
\hline Site of recurrence & & & .377 & \\
\hline No recurrence & $41(38.0)$ & $18(39.1)$ & & $2(25.0)$ \\
\hline Distant & $43(39.8)$ & $15(32.6)$ & & $2(25.0)$ \\
\hline Locoregional & $15(13.9)$ & $11(23.9)$ & & $1(12.5)$ \\
\hline Both distant and locoregional & $9(8.3)$ & $2(4.3)$ & & $3(37.5)$ \\
\hline
\end{tabular}

Values are presented as $\mathrm{n}(\%) . M I E$, Minimally invasive esophagectomy; $c T$, clinical T status; $n / r$, no record; $c N$, clinical $\mathrm{N}$ status; $L N$, lymph nodes.

statistical significance $(P=.170)$. We further analyzed DFS in ypTx N1 and ypTx N2 or N3 patients separately. The analysis was restricted to 2 years because after that time point $<10$ patients were at risk. We found that the DFS in ypTx N1 patients was similar between those who did or did not receive adjuvant treatment $(P=.490)$. However, in ypTx N2or N3 patients, the median DFS for those who received adjuvant treatment was 24.6 months, higher compared with 10.9 months for patients without adjuvant treatment. The DFS was found to be statistically significant in this subset of patients $(P=.007)$ (Figure 4).

\section{Multivariable Analysis}

In the multivariable analysis, the presence of locoregional and distant recurrence were independent factors for worse OS in patients with residual LNs (Table 3). On the other hand, adjuvant treatment was strongly associated with increased OS in patients with residual LN disease with HR 0.590 (95\% CI, 0.360-0.980). In regard to DFS, only the presence of venous invasion and a more advanced ypN stage ( $\mathrm{N} 2$ or N3) were significant prognosticators for worse DFS with HR 2.140 (95\% CI, 1.090-4.180) and HR 1.664 (95\% CI, 1.117-2.479), respectively (Table 3).

\section{DISCUSSION}

Our results showed a $22.0 \%$ rate of pathologic CR, consistent with published reports of the outcomes of patients with AC after nCRT. ${ }^{2,17}$ Residual LN disease regardless of primary tumor response was found in $31.8 \%$ of patients and was associated with significantly worse OS and DFS compared with patients with CR or with persistent disease only at the primary tumor level (Figure 2). We also examined the effect of ypT status on OS and DFS in $\mathrm{LN}+$ patients with residual LNs and ypT was not found to be an independent prognostic factor in the multivariate analyses.

Our study further demonstrated that patients with residual LN disease have higher rates of distant versus locoregional recurrence. The administration of adjuvant treatment had a significant positive prognostic effect on OS. This finding was consistent with the report by Samson and colleagues ${ }^{13}$ that demonstrated the beneficial role of adjuvant chemotherapy in $\mathrm{OS}$ in $\mathrm{LN}$ positive patients. Similar results were derived by another study, which also showed improved survival in node positive patients after adjuvant treatment. ${ }^{18}$ Both of the aforementioned studies were based on the National Cancer Database (NCDB) and the rate of patients receiving adjuvant treatment was $15.3 \%$ and $10.7 \%$, respectively, although only in the former study patients with positive LNs were included. In our study, the rate of administration of adjuvant treatment in patients with residual LN disease was $29.9 \%$. Furthermore, we also showed that DFS was not significantly different between patients with or without adjuvant treatment. When examined separately based on the number of positive LNs, adjuvant treatment resulted in significantly higher DFS in ypTx N2 or N3 

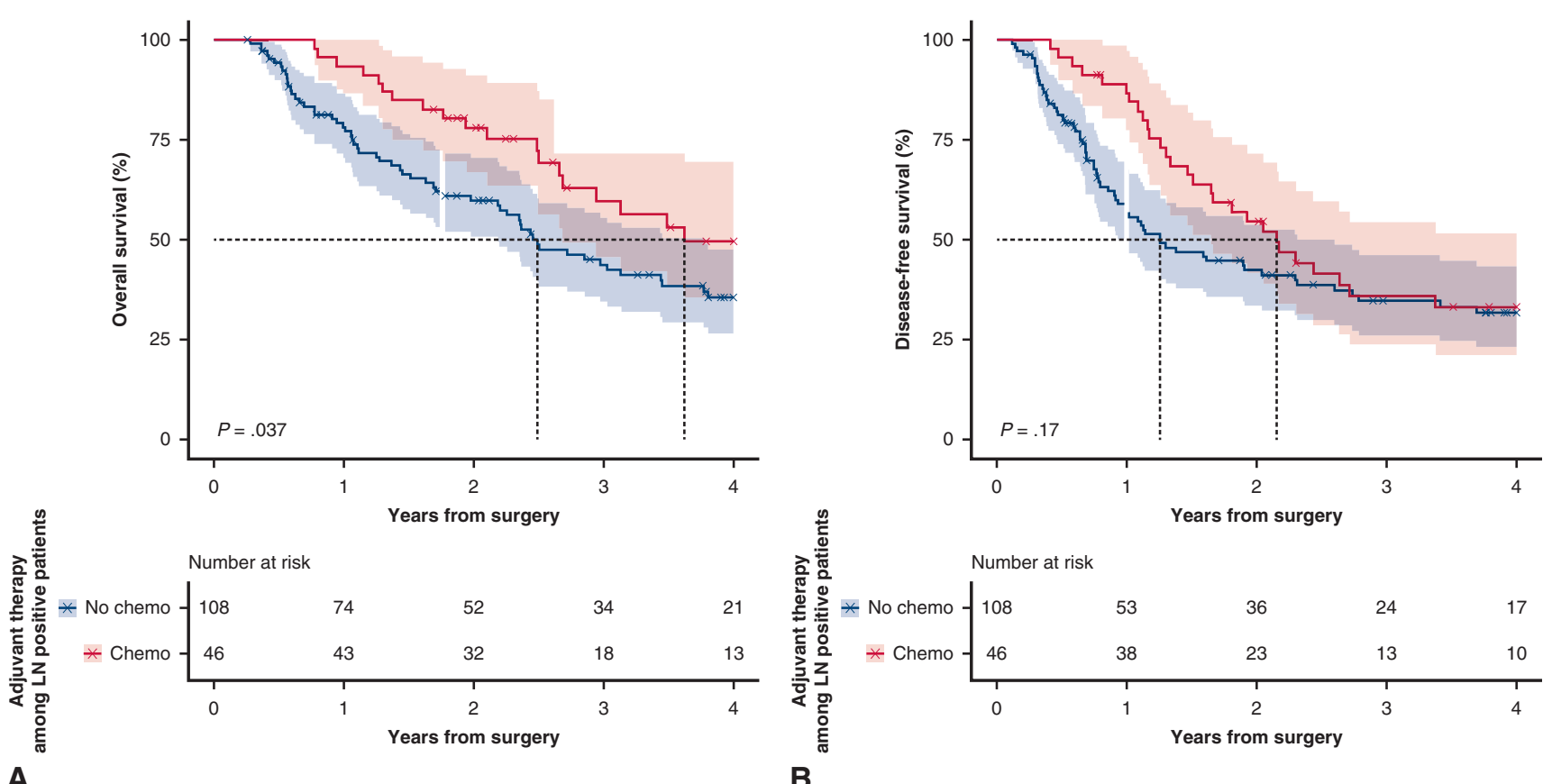

A
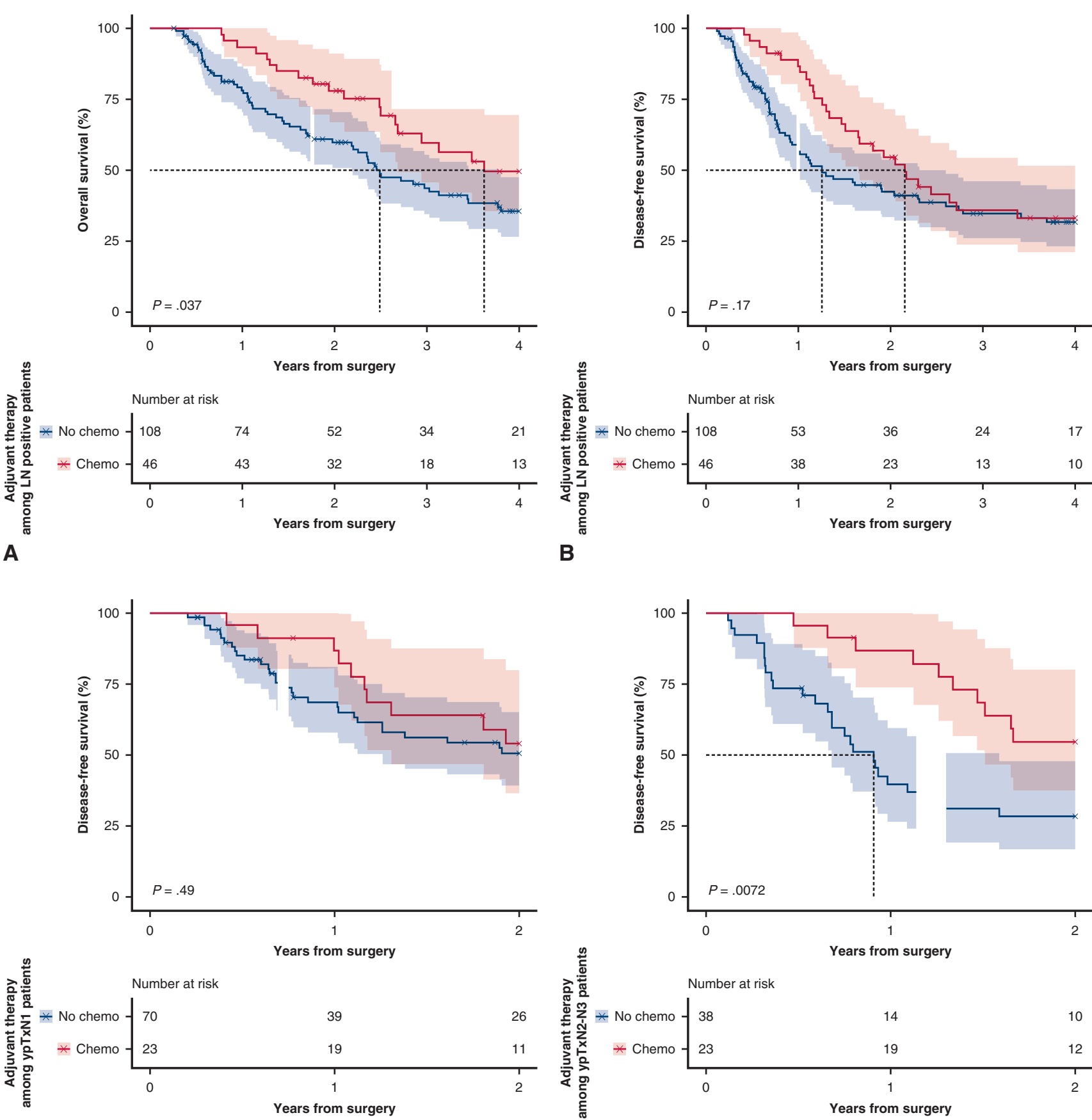

B

C
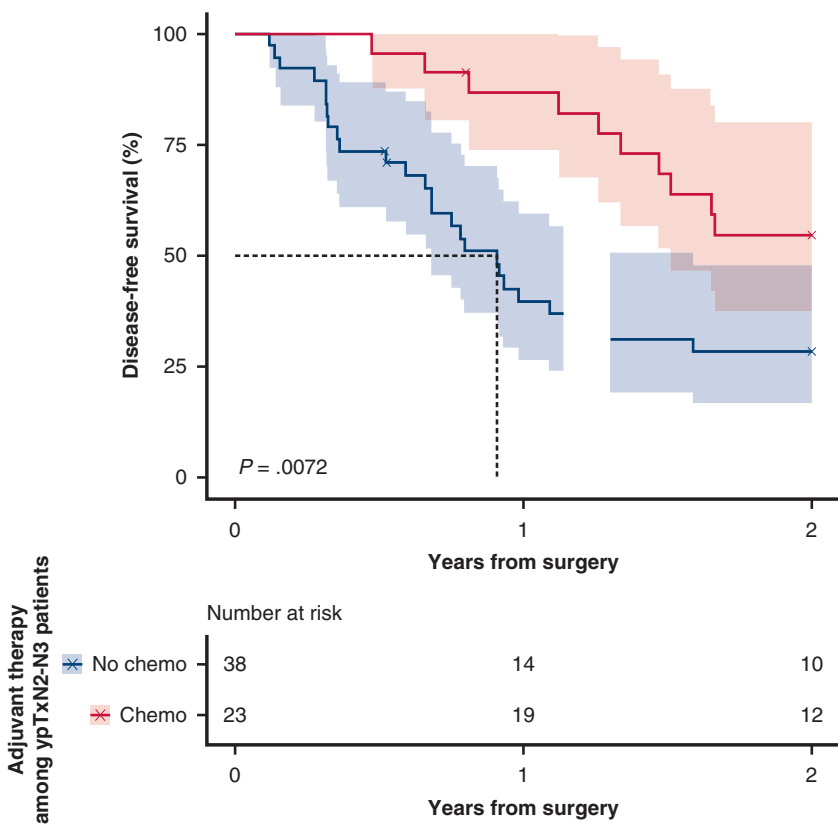

FIGURE 4. Survival curves based on the administration or not of adjuvant treatment in patients with residual lymph node (LN) disease. (The $x$-axis for survival in years was cut at the time point when $<10$ patients were at risk.). A, Overall survival (OS). The median OS in patients who received adjuvant treatment was 43.4 months (95\% confidence interval [CI], 32.1-62.7 months), higher compared with 29.8 months (95\% CI, 26.2-45.2 months) in patients who did not receive adjuvant treatment. B, Disease-free survival (DFS). The median DFS was 25.9 months (95\% CI, 19.8-32.8 months) in the group with adjuvant treatment and 15.1 months (95\% CI, 11.1-21.6 months) in the group without adjuvant treatment. C, DFS. The median DFS in ypTx N1 patients without adjuvant treatment was 31.2 months (95\% CI, 15.1-62.4 months) and 27.6 months (95\% CI, 17.2-38.1 months) in those with adjuvant treatment. D, DFS. The median DFS in ypTx N2 or N3 patients who received adjuvant treatment was 24.6 months (95\% CI, 16.3-33.0 months), higher compared with 10.9 months (95\% CI, 8.4-13.4 months) for patients without adjuvant treatment. 
TABLE 3. Cox regression analysis for overall and disease-free survival in patients with residual lymph node disease after neoadjuvant chemoradiation and esophagectomy

\begin{tabular}{|c|c|c|c|c|c|c|c|c|}
\hline \multirow[b]{4}{*}{ Variable } & \multicolumn{8}{|c|}{ Overall survival } \\
\hline & \multicolumn{4}{|c|}{ Univariate analysis } & \multicolumn{4}{|c|}{ Multivariate analysis } \\
\hline & \multirow[b]{2}{*}{ Hazard ratio } & \multicolumn{2}{|c|}{$95 \%$ confidence interval } & \multirow[b]{2}{*}{$P$ value } & \multirow[b]{2}{*}{ Hazard ratio } & \multicolumn{2}{|c|}{$95 \%$ confidence interval } & \multirow[b]{2}{*}{$P$ value } \\
\hline & & Lower & Upper & & & Lower & Upper & \\
\hline \multicolumn{9}{|l|}{ Age $(y)$} \\
\hline$\geq 65$ & Ref & & & & & & & \\
\hline$<65$ & 0.674 & 0.445 & 1.022 & .063 & & & & \\
\hline \multicolumn{9}{|l|}{ Gender } \\
\hline Male & Ref & & & & Ref & & & \\
\hline Female & 0.492 & 0.271 & 0.895 & .020 & 0.560 & 0.285 & 1.099 & .092 \\
\hline \multicolumn{9}{|l|}{ Type of surgery } \\
\hline Ivor Lewis & Ref & & & & & & & \\
\hline Three-hole & 1.116 & 0.735 & 1.694 & .606 & & & & \\
\hline \multicolumn{9}{|l|}{ Surgical approach } \\
\hline Hybrid & Ref & & & & & & & \\
\hline Open & 0.782 & 0.411 & 1.488 & .453 & & & & \\
\hline MIE & 0.550 & 0.302 & 1.002 & .051 & & & & \\
\hline \multicolumn{9}{|l|}{$\mathrm{cT}$} \\
\hline $\mathrm{T} 1-\mathrm{T} 2$ & Ref & & & & & & & \\
\hline $\mathrm{T} 3-\mathrm{T} 4$ & 0.876 & 0.493 & 1.554 & .650 & & & & \\
\hline \multicolumn{9}{|l|}{$\mathrm{cN}$} \\
\hline $\mathrm{cNO}$ & Ref & & & & & & & \\
\hline $\mathrm{cN} 1$ & 1.338 & 0.794 & 2.256 & .274 & & & & \\
\hline $\mathrm{cN} 2$ & 0.975 & 0.389 & 2.444 & .956 & & & & \\
\hline \multicolumn{9}{|l|}{ ypT status } \\
\hline урТ0-Т2 & Ref & & & & & & & \\
\hline урТ3-T4 & 1.007 & 0.638 & 1.590 & .975 & & & & \\
\hline \multicolumn{9}{|l|}{ ypN status } \\
\hline N1 & Ref & & & & & & & \\
\hline N2-N3 & 1.206 & 0.792 & 1.836 & .383 & & & & \\
\hline \multicolumn{9}{|l|}{ LNs removed } \\
\hline$\geq 15$ & Ref & & & & & & & \\
\hline$<15$ & 1.458 & 0.940 & 2.262 & .092 & & & & \\
\hline Grade & & & & & & & & \\
\hline $1-2$ & Ref & & & & & & & \\
\hline 3 & 1.135 & 0.736 & 1.750 & .568 & & & & \\
\hline Perineural invasior & & & & & & & & \\
\hline Absent & Ref & & & & & & & \\
\hline Present & 1.205 & 0.786 & 1.847 & .392 & & & & \\
\hline Lymphovascular ir & & & & & & & & \\
\hline Absent & Ref & & & & & & & \\
\hline Present & 1.427 & 0.928 & 2.194 & .105 & & & & \\
\hline Signet ring cells & & & & & & & & \\
\hline Absent & Ref & & & & & & & \\
\hline Present & 0.890 & 0.503 & 1.573 & .687 & & & & \\
\hline Venous invasion & & & & & & & & \\
\hline Absent & Ref & & & & Ref & & & \\
\hline Present & 2.096 & 1.082 & 4.059 & .028 & 1.020 & 0.460 & 2.250 & .960 \\
\hline Site of recurrence & & & & & & & & \\
\hline No recurrence & Ref & & & & Ref & & & \\
\hline Distant & 4.605 & 2.624 & 8.081 & $<.0001$ & 4.890 & 2.680 & 8.910 & $<.0001$ \\
\hline Locoregional & 3.560 & 1.870 & 6.782 & $<.0001$ & 3.600 & 1.820 & 7.130 & $<.0001$ \\
\hline
\end{tabular}


TABLE 3. Continued

\begin{tabular}{|c|c|c|c|c|c|c|c|c|}
\hline \multirow[b]{4}{*}{ Variable } & \multicolumn{8}{|c|}{ Overall survival } \\
\hline & \multicolumn{4}{|c|}{ Univariate analysis } & \multicolumn{4}{|c|}{ Multivariate analysis } \\
\hline & \multirow[b]{2}{*}{ Hazard ratio } & \multicolumn{2}{|c|}{$95 \%$ confidence interval } & \multirow[b]{2}{*}{$P$ value } & \multirow[b]{2}{*}{ Hazard ratio } & \multicolumn{2}{|c|}{$95 \%$ confidence interval } & \multirow[b]{2}{*}{$P$ value } \\
\hline & & Lower & Upper & & & Lower & Upper & \\
\hline \multicolumn{9}{|c|}{ Adjuvant chemotherapy } \\
\hline No & Ref & & & & Ref & & & \\
\hline \multirow[t]{5}{*}{ Yes } & 0.588 & 0.359 & 0.965 & .035 & 0.590 & 0.360 & 0.980 & .043 \\
\hline & \multicolumn{8}{|c|}{ Disease-free survival } \\
\hline & \multicolumn{4}{|c|}{ Univariate analysis } & \multicolumn{4}{|c|}{ Multivariate analysis } \\
\hline & & \multicolumn{2}{|c|}{$\mathbf{9 5} \%$ confidence interval } & \multirow[b]{2}{*}{$P$ value } & \multirow[b]{2}{*}{ Hazard ratio } & \multicolumn{2}{|c|}{$95 \%$ confidence interval } & \\
\hline & Hazard ratio & Lower & Upper & & & Lower & Upper & $P$ value \\
\hline Age (y) & & & & & & & & \\
\hline$\geq 65$ & Ref & & & & & & & \\
\hline$<65$ & 0.972 & 0.651 & 1.453 & .891 & & & & \\
\hline Gender & & & & & & & & \\
\hline Male & Ref & & & & & & & \\
\hline Female & 0.639 & 0.362 & 1.129 & .123 & & & & \\
\hline Type of surgery & & & & & & & & \\
\hline Ivor Lewis & Ref & & & & & & & \\
\hline Three-hole & 0.916 & 0.612 & 1.371 & 669 & & & & \\
\hline Surgical approach & & & & & & & & \\
\hline Hybrid & Ref & & & & & & & \\
\hline Open & 0.691 & 0.374 & 1.276 & .237 & & & & \\
\hline MIE & 0.600 & 0.349 & 1.031 & .064 & & & & \\
\hline $\mathrm{cT}$ & & & & & & & & \\
\hline $\mathrm{T} 1-\mathrm{T} 2$ & Ref & & & & & & & \\
\hline T3-T4 & 1.134 & 0.636 & 2.021 & .669 & & & & \\
\hline $\mathrm{cN}$ & & & & & & & & \\
\hline $\mathrm{cNO}$ & Ref & & & & & & & \\
\hline $\mathrm{cN} 1$ & 1.338 & 0.822 & 2.178 & .241 & & & & \\
\hline $\mathrm{cN} 2$ & 1.161 & 0.534 & 2.522 & .706 & & & & \\
\hline ypT status & & & & & & & & \\
\hline урТ0-T2 & Ref & & & & & & & \\
\hline урТ3-T4 & 1.241 & 0.806 & 1.911 & .327 & & & & \\
\hline ypN status & & & & & & & & \\
\hline N1 & Ref & & & & Ref & & & \\
\hline N2-N3 & 1.759 & 1.188 & 2.604 & .004 & 1.664 & 1.117 & 2.479 & .014 \\
\hline LNs removed & & & & & & & & \\
\hline$\geq 15$ & Ref & & & & & & & \\
\hline$<15$ & 1.045 & 0.665 & 1.6434 & .848 & & & & \\
\hline Grade & & & & & & & & \\
\hline $1-2$ & Ref & & & & & & & \\
\hline 3 & 1.397 & 0.911 & 2.142 & .125 & & & & \\
\hline Perineural invasio & & & & & & & & \\
\hline Absent & Ref & & & & & & & \\
\hline Present & 1.440 & 0.962 & 2.156 & .076 & & & & \\
\hline Lymphovascular i & & & & & & & & \\
\hline Absent & Ref & & & & & & & \\
\hline Present & 1.337 & 0.888 & 2.013 & .163 & & & & \\
\hline Signet ring cells & & & & & & & & \\
\hline Absent & Ref & & & & & & & \\
\hline Present & 0.891 & 0.522 & 1.521 & .672 & & & & \\
\hline
\end{tabular}


TABLE 3. Continued

\begin{tabular}{|c|c|c|c|c|c|c|c|c|}
\hline & \multicolumn{8}{|c|}{ Disease-free survival } \\
\hline & \multicolumn{4}{|c|}{ Univariate analysis } & \multicolumn{4}{|c|}{ Multivariate analysis } \\
\hline & \multirow[b]{2}{*}{ Hazard ratio } & \multicolumn{2}{|c|}{$95 \%$ confidence interval } & \multirow[b]{2}{*}{$P$ value } & \multirow[b]{2}{*}{ Hazard ratio } & \multicolumn{2}{|c|}{$\mathbf{9 5} \%$ confidence interval } & \multirow[b]{2}{*}{$P$ value } \\
\hline & & Lower & Upper & & & Lower & Upper & \\
\hline \multicolumn{9}{|c|}{ Venous invasion } \\
\hline Absent & Ref & & & & Ref & & & \\
\hline Present & 2.468 & 1.275 & 4.775 & .007 & 2.140 & 1.090 & 4.180 & .026 \\
\hline \multicolumn{9}{|c|}{ Adjuvant chemotherapy } \\
\hline No & Ref & & & & & & & \\
\hline Yes & 0.696 & 0.447 & 1.083 & .108 & & & & \\
\hline
\end{tabular}

Ref, Reference group; $M I E$, minimally invasive esophagectomy, $c T$, clinical T status; $c N$, clinical N status; $L N$, lymph nodes.

patients, but not in ypTx N1. The studies based on the NCDB do not provide results regarding DFS.

We divided our patients into groups for comparison based on the ypN status because the number of positive LNs determines $\mathrm{N}$ stage and was hypothesized to be a more crucial prognosticator than the primary tumor staging. The primary role of residual nodal status in prognosis compared with ypT stage was demonstrated in a study based on the NCDB. ${ }^{19}$ They reported that ypT0 N1 patients had equivalent survival to $\mathrm{T} 1$ or $\mathrm{T} 2 \mathrm{~N}+$ patients and improved survival only compared with T3 or T4 N+ patients. Depyrere and colleagues $^{3}$ also showed that ypT0 $\mathrm{N}+$ behave similarly to $\mathrm{ypT}+\mathrm{N}+$ patients without significant differences in OS and DFS regardless of histology. They subdivided the 2 groups based on the number of positive LNs in N1 and $\mathrm{N} 2$ or N3. There was a discrepancy in the numbers with 11 patients in the ypT0 N1 group, 3 in ypT0 N2 or N3, 55 in ypT $+\mathrm{N} 1$, and 57 patients in the ypT $+\mathrm{N} 2$ or $\mathrm{N} 3$, and they showed significantly worse OS in patients with higher number of positive LNs in both subgroups (2.7 compared with 21.7 months in ypT0 $\mathrm{N}+$ and 16.2 compared with 33.7 months in ypT $+\mathrm{N}+$, respectively). We showed that between the 2 subgroups ypTx N1 and ypTx N2 or N3, there was statistically significant difference in DFS, but not in OS. When compared with the aforementioned results by Depyrere and collegues ${ }^{3}$ our study group included only 3 patients with ypT0 $\mathrm{N}+$ status (vs 14 patients) and 169 patients with ypT $+\mathrm{N}+$ status (vs 112 patients).

Our results also demonstrated that the number of LNs retrieved did not differ significantly among the initial 3 groups of patients. There was also a trend toward higher LN harvest in more recent years in our practice. However, no association between the extent of lymphadenectomy and OS was identified in the whole cohort or in the subgroup analysis. This is consistent with the report by Shridhar and colleagues $^{20}$ that did not show an association between the number of LNs harvested during esophagectomy following nCRT and OS. Okholm and colleagues ${ }^{19}$ also did not demonstrate any significant difference in survival between a standard and an extended lymphadenectomy for esophagogastric AC. Instead of the number of LNs retrieved, the authors used $\mathrm{LN}$ stations to assess the extent of lymphadenectomy. They also reported that metastases in distant LNs were associated with poor survival and potentially disseminated disease. ${ }^{20}$ The above studies align with an earlier population-based study by van der Schaaf and colleages, ${ }^{21}$ which failed to support an association between extensive lymph node resection and increased survival in esophageal cancer, but they showed that a higher $\mathrm{LN}$ ratio was associated with significantly negative influence on OS. The cut-off value for the $\mathrm{LN}$ ratio can vary and in this particular study, 3 groups were created with $\mathrm{LN}$ ratios $<0.03,0.04$ to 0.038 , and $>0.038$, respectively. The HR for OS was highest (3.2) for $\mathrm{LN}$ ratio $>0.038 .{ }^{21}$ In our study, the LN ratio with a cut-off value of 0.2 was not found to be an independent factor for OS or DFS. The concept and clinical relevance of $\mathrm{LN}$ ratio have been challenged due to confounding factors, such as lymphadenectomy quality and influence of pathologic review in regard to LNs examined. ${ }^{22}$

The limitations of our study include its retrospective nature, the fact that the cause of death was not always related to esophageal cancer, and also the lack of all clinical data for the total of patients included. Nevertheless, the latter was taken into account during the statistical analysis. The type of adjuvant chemotherapy regimen was not consistent. Forty-two patients (42 out of 95 [44.2\%]) had at least 1 cycle of a chemotherapy regiment mad up of folinic acid, fluorouracil, and oxaliplatin and 33 patients received more than 1 regimen $(34.7 \%)$. Variables, such as intolerance to treatment, cycles completed, enrolment in clinical trials, palliative treatment, patient's wishes, and timing of administration in relation to surgery were not recorded.

\section{CONCLUSIONS}

Important conclusions from our study include further supporting evidence for the prognostic significance of residual $\mathrm{LN}$ disease after $\mathrm{nCRT}$ in esophageal $\mathrm{AC}$ and the strong association with distant recurrence and poor prognosis. Furthermore, there was no statistically significant 
difference in the OS between residual $\mathrm{N} 1$ and $\mathrm{N} 2$ or N3 subgroups, although DFS was better for patients with only N1 disease. Within the limitations of our study, the potential beneficial role of adjuvant treatment in patients with residual LN disease was also underlined; however, further research is required in this respect, especially in the form of a randomized controlled trial. Our current practice is to move toward a more individualized approach for patients with residual LN disease depending on tumor biology and a patient's comorbidities.

\section{Conflict of Interest Statement}

The authors reported no conflicts of interest.

The Journal policy requires editors and reviewers to disclose conflicts of interest and to decline handling or reviewing manuscripts for which they may have a conflict of interest. The editors and reviewers of this article have no conflicts of interest.

\section{References}

1. Shapiro J, van Lanschot JJB, Hulshof MCCM, van Hagen P, van Berge Henegouwen MI, Wijnhoven BPL, et al. Neoadjuvant chemoradiotherapy plus surgery versus surgery alone for oesophageal or junctional cancer (CROSS): long-term results of a randomised controlled trial. Lancet Oncol. 2015;16: 1090-8.

2. van Hagen P, Hulshof MC, van Lanschot JJ, Steyerberg EW, van Berge Henegouwen MI, Wijnhoven BP, et al. Preoperative chemoradiotherapy for esophageal or junctional cancer. N Engl J Med. 2012;366:2074-84.

3. Depypere LP, Nafteux PR. Extracapsular lymph node involvement after neoadjuvant chemoradiation in esophageal carcinoma: how to interpret? J Thorac Dis. 2017;9:E1143-4.

4. Donahue JM, Nichols FC, Li Z, Schomas DA, Allen MS, Cassivi SD, et al. Complete pathologic response after neoadjuvant chemoradiotherapy for esophageal cancer is associated with enhanced survival. Ann Thorac Surg. 2009;87:392-8.

5. Rice TW, Ishwaran H, Hofstetter WL, Schipper PH, Kesler KA, Law S, et al. Esophageal cancer: associations with $(\mathrm{pn}+)$ lymph node metastases. Ann Surg. 2017;265:122-9.

6. National Comprehensive Cancer Network. Guidelines: esophageal and esophagogastric junction cancers. Version 1; 2020. Available at: https://www.ncen. org/professionals/physician_gls/pdf/esophageal.pdf. Accessed December 18, 2020.

7. Robb WB, Dahan L, Mornex F, Maillard E, Thomas PA, Meunier B, et al. Impact of neoadjuvant chemoradiation on lymph node status in esophageal cancer: post hoc analysis of a randomized controlled trial. Ann Surg. 2015;261:902-8.

8. Lutfi W, Martinez-Meehan D, Dhupar R, Christie N, Sarkaria I, Ekeke C, et al. Higher lymph node harvest in patients with a pathologic complete response after neoadjuvant therapy for esophageal cancer is associated with improved survival J Surg Oncol. 2020;121:654-61.

9. Koen Talsma A, Shapiro J, Looman CW, van Hagen P, Steyerberg EW, van der Gaast A, et al. Lymph node retrieval during esophagectomy with and without neoadjuvant chemoradiotherapy: prognostic and therapeutic impact on survival. Ann Surg. 2014;260:786-92.

10. Noordman BJ, van Klaveren D, van Berge Henegouwen MI, Wijnhoven BPL, Gisbertz SS, Lagarde SM, et al. Impact of surgical approach on long-term survival in esophageal adenocarcinoma patients with or without neoadjuvant chemoradiotherapy. Ann Surg. 2018;267:892-7.

11. Ho HJ, Chen HS, Hung WH, Hsu PK, Wu SC, Chen HC, et al. Survival impact of total resected lymph nodes in esophageal cancer patients with and without neoadjuvant chemoradiation. Ann Surg Oncol. 2018:25:3820-32.

12. Semenkovich TR, Subramanian M, Yan Y, Hofstetter WL, Correa AM, Cassivi SD, et al. Adjuvant therapy for node-positive esophageal cancer after induction and surgery: a multisite study. Ann Thorac Surg. 2019;108: 828-36.

13. Samson P, Puri V, Lockhart AC, Robinson C, Broderick S, Patterson GA, et al. Adjuvant chemotherapy for patients with pathologic node-positive esophageal cancer after induction chemotherapy is associated with improved survival. $J$ Thorac Cardiovasc Surg. 2018;156:1725-35.

14. Mariette C, Piessen G, Briez N, Triboulet JP. The number of metastatic lymph nodes and the ratio between metastatic and examined lymph nodes are independent prognostic factors in esophageal cancer regardless of neoadjuvant chemoradiation or lymphadenectomy extent. Ann Surg. 2008;247:365-71.

15. Swanson SJ, Sugarbaker DJ. The three-hole esophagectomy. The Brigham and Women's Hospital approach (modified McKeown technique). Chest Surg Clin N Am. 2000;10:531-52.

16. Greenstein AJ, Litle VR, Swanson SJ, Divino CM, Packer S, Wisnivesky JP. Prognostic significance of the number of lymph node metastases in esophageal cancer. J Am Coll Surg. 2008;206:239-46.

17. Stiles BM, Kamel MK, Harrison SW, Rahouma M, Lee B, Nasar A, et al. Neoadjuvant therapy for locally advanced esophageal cancer should be targeted to tumor histology. Ann Thorac Surg. 2019;107:187-93.

18. Takahashi C, Shridhar R, Huston J, Meredith K. Clinical fate of T0N1 esophageal cancer: results from the national cancer database. J Gastrointest Oncol. 2018;9: 880-6.

19. Okholm C, Fjederholt KT, Mortensen FV, Svendsen LB, Achiam MP. The optimal lymph node dissection in patients with adenocarcinoma of the esophagogastric junction. Surg Oncol. 2018;27:36-43.

20. Shridhar R, Hoffe SE, Almhanna K, Weber JM, Chuong MD, Karl RC, et al Lymph node harvest in esophageal cancer after neoadjuvant chemoradiotherapy. Ann Surg Oncol. 2013;20:3038-43.

21. van der Schaaf M, Johar A, Wijnhoven B, Lagergren P, Lagergren J. Extent of lymph node removal during esophageal cancer surgery and survival. J Natl Cancer Inst. 2015;107:djv043.

22. Rice TW, Blackstone EH. Lymph node ratio: a confounded quotient. Ann Thorac Surg. 2013;96:744.

Key Words: esophageal cancer, adenocarcinoma esophagus, nodal disease, persistent nodal disease, adjuvant therapy, pathologic staging 